\title{
Produção de crisântemo (Dendranthema grandiflora Tzvelev.) 'Snowdon' em vaso I: doses e freqüências de aplicação de daminozide
}

\author{
Production of chrysanthemum (Dendranthema grandiflora Tzvelev.), cv. 'Snowdon', in pots I: daminozide's \\ concentrations and times of application
}

\author{
Jucelma de Cássia Câmara Tolotti ${ }^{1}$ Rogério Antônio Bellé Leandro Mainardi $^{3}$
}

\section{RESUMO}

\begin{abstract}
O trabalho teve como objetivo avaliar a resposta de crisântemo através da análise de parâmetros fenométricos, ao redutor de crescimento Daminozide, pulverizado na cultivar de crisântemo de corte "Snowdon", cultivada em vaso. O estudo foi formado por dois ensaios com cinco repetições, usando delineamento experimental inteiramente casualizado em esquema fatorial $4 \times 2$, sendo formado por quatro doses de Daminozide (0, 2.000, 4.000 e $\left.6.000 \mathrm{mg} . \mathrm{L}^{-1}\right)$ e duas freqüencias de aplicações (semanal e bissemanal). Os resultados evidenciaram que as diferentes doses e freqüencias de aplicações reduziram a altura da planta, o número de nós, o comprimento de entrenós, o diâmetro da inflorescência e o comprimento do pedúnculo floral. Entretanto, constatou-se aumento dos diâmetros da haste e do pedúnculo floral. Na dose $4.000 \mathrm{mg} . \mathrm{L}^{-1}$ aplicada semanalmente, produziram-se os vasos de melhor qualidade, com altura da planta nos padrões recomendados para comercialização.
\end{abstract}

Palavras-chave: redutor de crescimento, daminozide (ácido succínico - 2, 2 - dimetilhidrazida), B-9, dose, altura de planta, diâmetro da haste, diâmetro da inflorescência.

\section{ABSTRACT}

The aim of this study was to investigate the response of potted chrysanthemum $\mathrm{cv}$. Snowdon, to the growth retardant Daminozide, in terms of fenometric parameters. The study consisted of two experiments with five repetitions. The experiments were bifactorial $4 \times 2$, with four concentrations of Daminozide $(0,2,000,4,000$ and $6,000 \mathrm{mg} \cdot \mathrm{L}^{-1}$ ) and two times of application (weekly and biweekly) of the product. Plant height, number of nodes, length of internodes, diameter of stems and inflorescences, length and diameter of floral peduncle were determinated. All concentrations and times of applications were able to reduce plant height, length of internodes, flower diameter and floral peduncle length. However, the diameter of the stem and floral peduncle were increased. The weekly application of 4,000 mg. $\mathrm{L}^{-1}$ Daminozide produced plants with the best quality within the commercial standards.

Key words: growth retardant, succinic acid 2,2-dimethylhydrazide (daminozide), B-nine, concentration, plant height, stem diameter, flower diameter.

\section{INTRODUÇÃO}

O cultivo do crisântemo em vaso, no Rio Grande do Sul, é ainda muito limitado, devido a dificuldades técnicas para sua produção e necessidade de maior investimento do ambiente para garantir a produção o ano todo. As cultivares de vaso disponíveis no mercado brasileiro não satisfazem algumas necessidades, especialmente o tipo Bola para cultivo em regiões de temperatura baixa. Devido a essa limitação, é possível utilizarem-se as cultivares de corte, cultivadas em vaso, que são conduzidas com a diminuição do porte (BELLÉ, 1997). Entre as cultivares de corte, a "Snowdon" e a "Yellow Snowdon" não apresentam limitações térmicas na produção. Por essa razão, a produção destas cultivares em vaso, pode se tornar um produto diferenciado, permitindo uma melhor comercialização.

As plantas de vaso, muitas vezes, apresentam comprimento maior que o desejado e por razões de padrão de produção e qualidade, geralmente

${ }^{1}$ Engenheiro Agrônomo, Doutorando do Programa de Pós-graduação em Agronomia, Departamento de Fitotecnia, Universidade Federal de Santa Maria (UFSM). E-mail: lemain@terra.com.br. Autor para correspondência.

${ }^{2}$ Engenheiro Agrônomo, Doutor, Professor, Departamento de Fitotecnia, UFSM, 97105-900-Santa Maria, RS. E-mail: bellé@ccr.ufsm.br.

${ }^{3}$ Engenheiro Agrônomo, Especialista em Administração e Desenvolvimento Rural, Autônomo, Santa Maria, RS. 
é necessária a redução do seu porte. É possível produzir plantas com tamanho reduzido através do uso de redutores químicos do crescimento.

O tratamento com esses produtos é feito durante a fase de rápido crescimento vegetativo ou mesmo logo após o início do florescimento, quando as plantas estão no tamanho limite da altura (HERTWIG, 1977; HARTMANN et al., 1988).

Os retardadores de crescimento atuam na planta reduzindo a produção natural de giberelina, modificando sua morfologia, formando plantas compactas. Esses afetam a formação de células e a elongação do internódio abaixo do meristema, assim plantas baixas são obtidas com o desenvolvimento de flores normais. O comprimento do internódio é reduzido, contudo o número de internódios normalmente não é afetado. Além disso, as folhas são menores e ficam com um verde mais intenso (BARRET, 1992). Especificamente sobre o redutor de crescimento Daminozide, conhecido comercialmente como Sadh, Alar-85, B-nine e Kilar, BARRET (1992) descreve que o produto é aplicado somente via foliar e é muito móvel em todas as partes da planta após aplicação. Sua concentração em pulverização é geralmente de 1.250 a $5.000 \mathrm{mg} . \mathrm{L}^{-1} \mathrm{e}$ seu efeito depende de alguns fatores como idade da planta e temperatura.

No entanto, LOPES (1977) explica que a freqüência e dosagem das aplicações de Daminozide dependem da variedade que está sendo cultivada, estação do ano, tamanho da planta, tamanho do vaso. Este autor recomenda que o produto seja aplicado de 1 a 4 vezes, em média, durante o ciclo, utilizando-se de 2.000 a $3.000 \mathrm{mg} . \mathrm{L}^{-1}$. Mas há casos em que são necessárias mais de 4 aplicações para que o vaso atinja o porte ideal para o mercado.

Estudos conduzidos por TAYAMA (1992) mostraram que para cultivares muito sensíveis, os melhores resultados utilizando o Daminozide foram obtidos com a concentração de $0,25 \%$ (2.500 mg. $\left.\mathrm{L}^{-1}\right)$, aplicados quando as plantas atingiram a altura final desejada. Para cultivares sensíveis ou pouco sensíveis, a melhor concentração foi de $0,5 \%\left(5.000 \mathrm{mg} . \mathrm{L}^{-1}\right)$, pulverizando o produto quando as brotações laterais estavam com 4 a $5 \mathrm{~cm}$ de comprimento. Entretanto, aplicações posteriores podem ser necessárias após 2 semanas. Se estas forem realizadas 4 semanas antes do período de florescimento, poderão afetar a coloração das flores, principalmente em cultivares brancas.

Cathey (1967), apud YAMADA (1992), explica que para o crisântemo de vaso, a utilização de Sadh (Daminozide) 2.500 e $5.000 \mathrm{mg} . \mathrm{L}^{-1}$ aplicados na segunda semana de dias curtos, além de assegurar o porte ideal, aumentou o tamanho e também melhorou o formato das inflorescências.

Em pesquisa realizada por CATHEY (1975) o crisântemo respondeu ao Daminozide pela lenta elongação da haste, mas o número de nós não foi alterado, mesmo com concentrações muito elevadas.

Em ensaios realizados por EL-KELTAWI et al. (1996) a aplicação foliar de Daminozide reduziu 18,2\% a altura das plantas de crisântemo, quando comparadas com o tamanho das testemunhas.

O presente trabalho teve como objetivo avaliar a resposta do crisântemo de corte "Snowdon", de inflorescências grandes e de alto vigor, cultivado em vaso através de parâmetros fenométricos, ao redutor de crescimento Daminozide.

\section{MATERIAL E MÉTODOS}

Foram conduzidos dois ensaios em casa de vegetação, pertencente ao Setor de Floricultura, do Departamento de Fitotecnia, da Universidade Federal de Santa Maria, RS, Brasil (latitude 29 43'S, longitude $53^{\circ} 42^{\prime}$ W e altitude $95 \mathrm{~m}$ ).

Os ensaios foram bifatoriais $4 \times 2$ no delineamento inteiramente casualizado, com cinco repetições. O primeiro fator foi composto por quatro doses $\left(0,2.000,4.000\right.$ e $\left.6.000 \mathrm{mg} . \mathrm{L}^{-1}\right)$ do redutor químico de crescimento Daminozide, quimicamente puro (ácido succínico-2,2-dimetilhidrazida), diluído em água destilada e pulverizado sobre as folhas. $\mathrm{O}$ outro fator foi constituído por duas épocas de aplicação do redutor, ou seja, a metade de cada ensaio teve freqüência de aplicação semanal ( 7 em 7 dias) e a outra metade freqüência de aplicação bissemanal (14 em 14 dias).

A cultivar utilizada foi a "Snowdon", conduzida em haste única. Esta cultivar é classificada como: tipo Bola, ciclo longo (9 semanas) e cor branca. É utilizada para corte, possui inflorescência grande e hastes longas. Foi especialmente melhorada para ser conduzida com uma única inflorescência, cujo diâmetro pode chegar a mais de $20 \mathrm{~cm}$. Colocaram-se três estacas sem raiz diretamente no vaso número 15 em 24/03/99 e, em seguida, foram postas para enraizar (sob condições de dia longo - DL) em câmara úmida por 14 dias. Após o enraizamento, o ensaio 1 permaneceu em dia longo por mais uma semana (até 14/04/99) e o ensaio 2 por mais duas semanas (até 21/04/99). Para ambas as datas os vasos foram espaçados para 9 vasos $/ \mathrm{m}^{2}$ (MOTOS, 1998) e iniciaram-se as pulverizações com o Daminozide, ocorrendo a indução ao florescimento pelos dias curtos naturais, nos respectivos ensaios. As aplicações do produto finalizaram quando os 
botões florais estavam com $1,5 \mathrm{~cm}$ de diâmetro, totalizando nove aplicações semanais e cinco bissemanais para o ensaios 1 e oito aplicações semanais e quatro bissemanais para o ensaio 2. A adubação utilizada foi na proporção NPK de 2:0,3:1 até o surgimento dos botões florais para formação das hastes, massa foliar e raízes. Após essa fase, a proporção NPK foi de 1:0,3:2.

As determinações para os parâmetros avaliados foram efetuadas quando as plantas estavam em pleno florescimento, ou seja, no ponto de comercialização, coincidindo com a colheita dos ensaios, sendo avaliados altura de planta, número de nós, distância de entrenós, diâmetros da haste e da inflorescência, diâmetro e comprimento do pedúnculo floral. A análise estatística dos dados foi através do programa Software Científico (SOC). Efetuou-se a análise da variância e regressão dos dados, em nível de 5\% de significância.

\section{RESULTADOS E DISCUSSÃO}

Os resultados da análise da variância e de regressão para altura de planta, número de nós, comprimento de entrenós, diâmetros da haste, da inflorescência e do pedúnculo floral, e comprimento do pedúnculo floral, são apresentados na tabela 1. Observase que houve interação somente para altura de planta com uma e duas semanas de DL e para distância de entrenós com duas semanas de DL. Para o número de nós nenhum fator foi significativo.

Na figura 1, são mostrados os resultados referentes à altura de planta com freqüência de aplicação semanal e bissemanal para as doses de Daminozide. Em ambos os casos, a maior redução de altura foi obtida próxima à dose de $4.000 \mathrm{mg} . \mathrm{L}^{-1}$, independente do período de crescimento. As aplicações semanais de Daminozide reduziram a altura da planta, de forma semelhante à metade da altura total das plantas. O ponto de máxima eficiência técnica para o ensaio com uma semana de DL (Figura 1a) foi com a dose $4.464 \mathrm{mg} . \mathrm{L}^{-1}$ correspondendo à altura de $26,66 \mathrm{~cm}$, onde se obteve redução de $51,14 \%$ na altura. Para duas semanas de DL (Figura 1b), esse ponto foi na dose $4.411 \mathrm{ppm}$ com altura de $31,55 \mathrm{~cm}$, obtendo-se redução na altura de $51,18 \%$. Já nas aplicações bissemanais, obteve-se o ponto de máxima eficiência técnica com a dose $4.750 \mathrm{mg} . \mathrm{L}^{-1} \mathrm{e}$ altura de $30,99 \mathrm{~cm}$, para o ensaio com uma semana de DL e com a dose $4.454 \mathrm{mg} . \mathrm{L}^{-1}$ e altura de $38,33 \mathrm{~cm}$, para o ensaio com duas semanas de DL, sendo que as reduções de altura, nestes pontos, foram $42,14 \%$ e $36,29 \%$ respectivamente.

$\mathrm{O}$ efeito de redução na altura das plantas de crisântemo pelo Daminozide foi também constatado por NELL et al. (1980) em que a aplicação de 5.000mg.L-1 reduziu em $27 \%$ a altura da cv. "Yellow Mandalay" e em $47 \%$ a cv. Royal Trophy.

Através do estudo dos dados referentes ao número de nós das hastes, foi possível afirmar que tanto a interação entre as

Tabela 1 - Resumo da análise da variância para altura de planta, número de nós, distância de entrenós, diâmetro da haste, diâmetro da inflorescência, comprimento do pedúnculo floral e diâmetro do pedúnculo floral para as diferentes doses e freqüências de aplicação de Daminozide em crisântemo (Dendranthema grandiflora Tzvelev.), cultivar "Snowdon". Santa Maria, RS, 2001.

\begin{tabular}{|c|c|c|}
\hline Causas da variação & $\begin{array}{c}\text { Uma semana de } \\
\text { DL }\end{array}$ & $\begin{array}{l}\text { Duas semanas de } \\
\text { DL }\end{array}$ \\
\hline & Altura de planta & Altura de planta \\
\hline Freqüência (Freq) & $56,78^{*}$ & $68,09^{*}$ \\
\hline Dose & $1226,84^{*}$ & $1523,76^{*}$ \\
\hline \multirow[t]{2}{*}{ Interação Freq x Dose } & $27,83^{*} \mathrm{Q}$ & $63,89 * \mathrm{Q}$ \\
\hline & Número de nós & Número de nós \\
\hline Freqüência (Freq) & $9,34 \mathrm{~ns}$ & $2,03 \mathrm{~ns}$ \\
\hline Dose & $3,03 \mathrm{~ns}$ & $1,81 \mathrm{~ns}$ \\
\hline \multirow[t]{2}{*}{ Interação Freq x Dose } & $2,36 \mathrm{~ns}$ & $2,02 \mathrm{~ns}$ \\
\hline & $\begin{array}{l}\text { Distância de } \\
\text { entrenós }\end{array}$ & $\begin{array}{l}\text { Distância de } \\
\text { entrenós }\end{array}$ \\
\hline Freqüência (Freq) & $0,0006 \mathrm{~ns}$ & $0,20 *$ \\
\hline Dose & $1,89 * \mathrm{Q}$ & $1,98^{*}$ \\
\hline \multirow[t]{2}{*}{ Interação Freq x Dose } & $0,07 \mathrm{~ns}$ & $0,05^{*} \mathrm{Q}$ \\
\hline & $\begin{array}{l}\text { Diâmetro da } \\
\text { haste }\end{array}$ & $\begin{array}{l}\text { Diâmetro da } \\
\text { haste }\end{array}$ \\
\hline Freqüência (Freq) & $0,01^{*}$ & $0,004 \mathrm{~ns}$ \\
\hline Dose & $0,004 * \mathrm{~L}$ & $0,007 * \mathrm{~L}$ \\
\hline \multirow[t]{2}{*}{ Interação Freq x Dose } & $0,001 \mathrm{~ns}$ & $0,0004 \mathrm{~ns}$ \\
\hline & $\begin{array}{l}\text { Diâmetro da } \\
\text { infloresc. }\end{array}$ & $\begin{array}{l}\text { Diâmetro da } \\
\text { infloresc. }\end{array}$ \\
\hline Freqüência (Freq) & $1,52 *$ & $5,63^{*}$ \\
\hline Dose & $1,13 * \mathrm{Q}$ & $0,43 \mathrm{~ns}$ \\
\hline \multirow[t]{2}{*}{ Interação Freq x Dose } & $0,34 \mathrm{~ns}$ & $0,22 \mathrm{~ns}$ \\
\hline & $\begin{array}{l}\text { Comp. pedúnculo } \\
\text { floral }\end{array}$ & $\begin{array}{l}\text { Comp. pedúnculo } \\
\text { floral }\end{array}$ \\
\hline Freqüência (Freq) & $0,03 \mathrm{~ns}$ & $0,0001 \mathrm{~ns}$ \\
\hline Dose & $3,89 * \mathrm{Q}$ & $5,62 * \mathrm{Q}$ \\
\hline \multirow[t]{2}{*}{ Interação Freq x Dose } & $0,01 \mathrm{~ns}$ & $0,14 \mathrm{~ns}$ \\
\hline & $\begin{array}{l}\text { Diâm. pedúnculo } \\
\text { floral }\end{array}$ & $\begin{array}{l}\text { Diâm. pedúnculo } \\
\text { floral }\end{array}$ \\
\hline Freqüência (Freq) & $0,001 \mathrm{~ns}$ & $0,002 \mathrm{~ns}$ \\
\hline Dose & $0,004 * \mathrm{~L}$ & $0,01 * \mathrm{~L}$ \\
\hline Interação Freq x Dose & $0,001 \mathrm{~ns}$ & $0,001 \mathrm{~ns}$ \\
\hline
\end{tabular}

* = significativo em nível de $5 \%$ de probabilidade de erro; ns = não significativo;

$\mathrm{L}=$ modelo linear significativo pelo teste $\mathrm{F}$ em nível de $5 \%$ de probabilidade;

$\mathrm{Q}=$ modelo quadrático significativo pelo teste $\mathrm{F}$ em nível de $5 \%$ de probabilidade

Ciência Rural, v. 33, n. 6, nov-dez, 2003. 


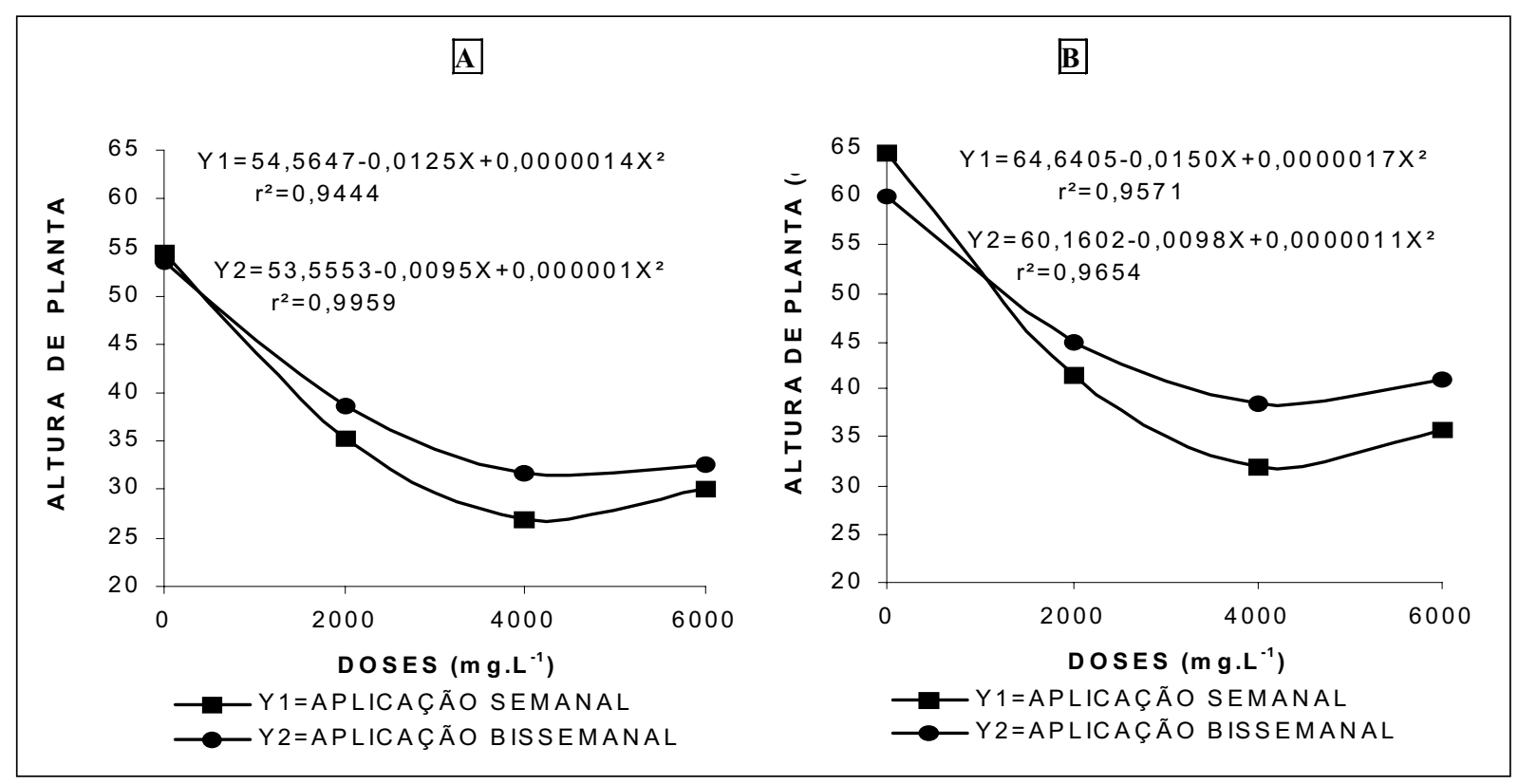

Figura 1 - Altura de plantas de crisântemo, cultivar "Snowdon", para doses de Daminozide com uma (A) e duas (B) semanas de dias longos. Santa Maria - RS. 2001.

diferentes doses e freqüências de aplicações como as mesmas agindo separadamente não influenciaram no número de nós das hastes (Tabela 1). As plantas tratadas com o redutor de crescimento apresentaram uma média de 23,62 nós.

Este resultado é concordante com os de CATHEY (1975) que utilizando Daminozide de $1.000 \mathrm{a}$ $10.000 \mathrm{mg} . \mathrm{L}^{-1} \mathrm{em} 88$ espécies diferentes, não obteve alteração no número de nós não foram alterados, mesmo com concentrações muito elevadas. BARRET (1992) também reforça este resultado, afirmando que, normalmente, o número de nós não é afetado pelos redutores de crescimento.

Quanto ao comprimento de entrenós, todas as doses de Daminozide no ensaio com uma semana de DL reduziram o mesmo. Para este ensaio, a maior redução ocorreu com a dose de $4.000 \mathrm{mg} . \mathrm{L}^{-}$ ${ }^{1}$ (Figura 2a), na qual houve uma diminuição de $40,69 \%$ em relação às plantas não tratadas. As freqüências não influenciaram nos resultados obtidos nesse ensaio, pois não houve diferença estatística entre as mesmas (Tabela 2). Já para o ensaio com duas semanas de DL houve interação de doses e freqüências de aplicações de Daminozide (Tabela 1). Observa-se que tanto para a freqüência semanal como bissemanal a diminuição da distância de entrenós foi acentuada
(Figura 2b) e a maior redução, dentre as doses testadas, foi com $4.000 \mathrm{mg} . \mathrm{L}^{-1}$ em aplicações bissemanais, sendo igual a $58,25 \%$.

A literatura consultada é quase unânime em afirmar que o principal efeito dos redutores de crescimento é a diminuição do comprimento de entrenós. A ação destes produtos ocorre por bloqueio da ação ou biossíntese das giberelinas e os maiores efeitos observados são sobre a elongação e divisão de células no meristema formador do entrenó (BARRET, 1992; TAIZ \& ZEIGER, 1998).

Desse modo, constata-se que a redução da altura das plantas encontrada nos diferentes ensaios é resultado da diminuição do comprimento de entrenós, uma vez que não houve modificação do número de nós produzidos pelas plantas tratadas com diferentes doses e freqüências de aplicações.

Os resultados de diâmetro da haste (Figura 3a) indicam que o diâmetro da haste aumentou com o aumento da dose. No ensaio com uma semana de DL, o aumento foi de $8,88 \%$ para a maior dose e no ensaio com duas semanas de DL foi de $12,56 \%$ com uma elevação de $4 \%$ entre cada dose. As freqüências influenciaram os resultados de diâmetro da haste no ensaio com uma semana de DL, sendo que a diferença entre a freqüência semanal e bissemanal foi em torno de 7\% (Tabela 2). O aumento do diâmetro da haste 
Tabela 2 - Altura de planta, número de nós, distância de entrenós, diâmetro da haste, diâmetro da inflorêscencia, comprimento do pedúnculo floral, diâmetro do pedúnculo floral, para diferentes períodos de dias longos (DL) e freqüências de aplicações (FA) de Daminozide em crisântemo (Dendranthema grandiflora Tzvelev.), cultivar "Snowdon". Santa Maria - RS, 2001.

\begin{tabular}{|c|c|c|c|c|}
\hline & \multicolumn{2}{|c|}{ DAMINOZIDE } & \multicolumn{2}{|c|}{ DAMINOZIDE } \\
\hline & \multicolumn{2}{|c|}{ Uma semana de DL } & \multicolumn{2}{|c|}{ Duas semanas de DL } \\
\hline & \multicolumn{2}{|c|}{ F A } & \multicolumn{2}{|c|}{ F A } \\
\hline VARIÁVEIS & Semanal & Bissemanal & Semanal & Bissemanal \\
\hline Altura de planta $(\mathrm{cm})$ & $37,09 \mathrm{~b}^{*}$ & $39,47 \mathrm{a}$ & $43,62 b^{*}$ & $46,23 \mathrm{a}$ \\
\hline Número de nós & $22,06 \mathrm{a}$ & $22,10 \mathrm{a}$ & $24,90 \mathrm{a}$ & 24,44 a \\
\hline Distância de entrenós (cm) & $1,38 \mathrm{a}$ & $1,38 \mathrm{a}$ & $1,37 b^{*}$ & $1,51 \mathrm{a}$ \\
\hline Diâm. da haste $(\mathrm{cm})$ & $0,52 \mathrm{a}^{*}$ & $0,48 \mathrm{~b}$ & $0,49 \mathrm{a}$ & $0,47 \mathrm{a}$ \\
\hline Diâm. inflorescência (cm) & $11,35 b^{*}$ & $11,74 \mathrm{a}$ & $10,57 b^{*}$ & $11,32 \mathrm{a}$ \\
\hline Comp. pedúnculo floral $(\mathrm{cm})$ & $1,28 \mathrm{a}$ & $1,34 \mathrm{a}$ & $0,92 \mathrm{a}$ & $0,92 \mathrm{a}$ \\
\hline Diâm.pedúnculo floral (cm) & $0,46 \mathrm{a}$ & $0,45 \mathrm{a}$ & $0,47 \mathrm{a}$ & $0,49 \mathrm{a}$ \\
\hline
\end{tabular}

* Médias não seguidas pela mesma letra na horizontal diferem entre si, pelo Teste de Duncan em nível de 5\% de probabilidade do erro.

com o aumento das doses não significou maior resistência das mesmas, pois até as menores plantas, com hastes mais espessas não foram capazes de suportar a inflorescência e necessitaram de tutoramento.

$\mathrm{Na}$ análise do diâmetro da inflorescência, encontrou-se que, para o ensaio com uma semana de DL (Figura 3b) e dentre as doses aplicadas, aquela que causou maior redução foi a de $4.000 \mathrm{mg} . \mathrm{L}^{-1}$, diminuindo em $6 \%$ o diâmetro. Quanto à freqüência de aplicação, esta foi significativa nos dois ensaios e a diferença estatística é apresentada na Tabela 2. Nesta, observa-se que a freqüência semanal é inferior à bissemanal em ambos os ensaios, indicando que, quando a freqüência foi diminuída, maior foi a redução constatada.

Os trabalhos que avaliam o diâmetro da inflorescência, quando tratada com redutores de

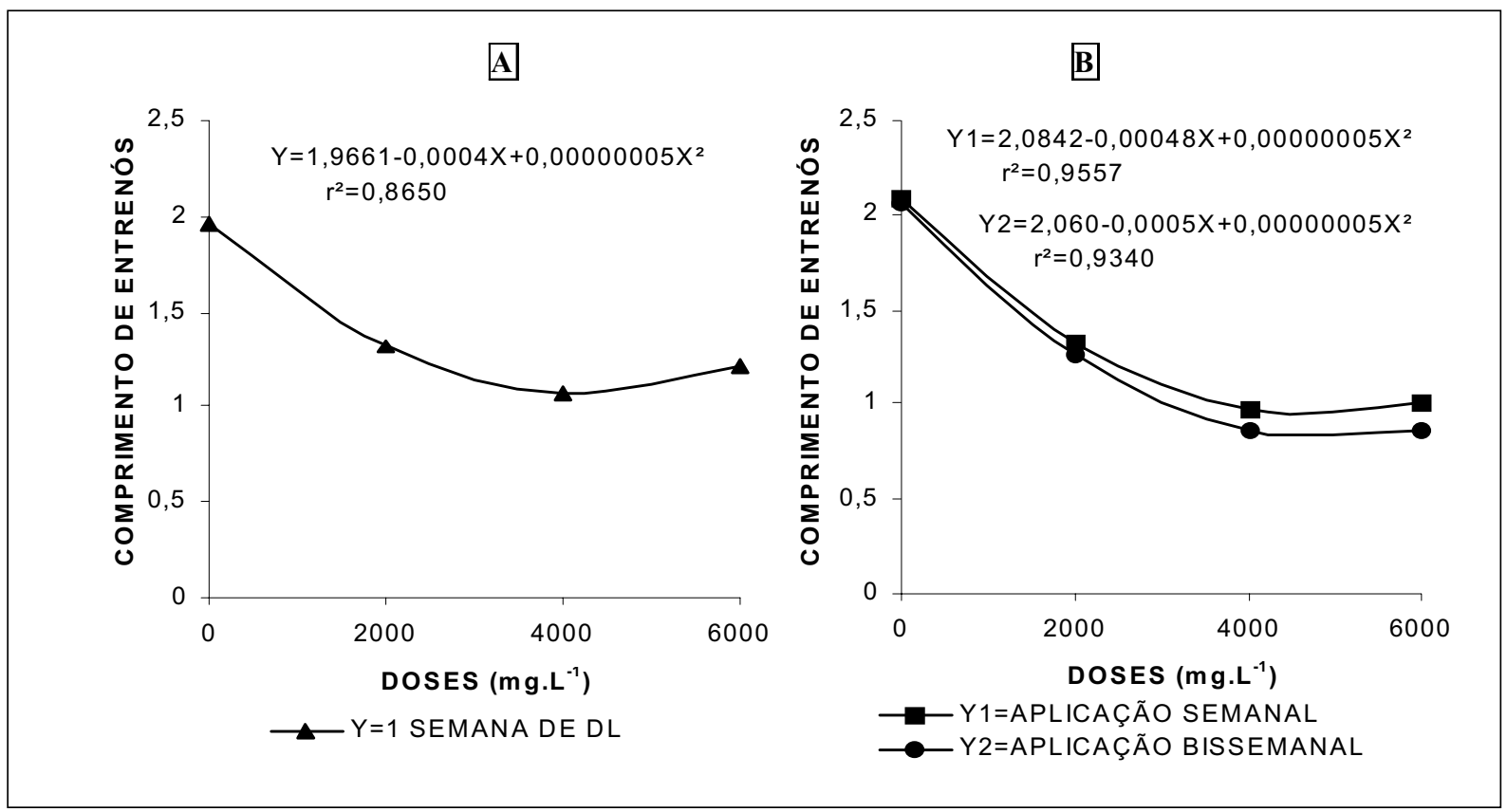

Figura 2 - Comprimento de entrenós de crisântemo (cm), cultivar "Snowdon" para doses de Daminozide com uma semna de dias longo (A) e duas semanas de dias longos (B). Santa Maria - RS. 2001.

Ciëncia Kural, v. 33, n. 6, nov-dez, 2003. 


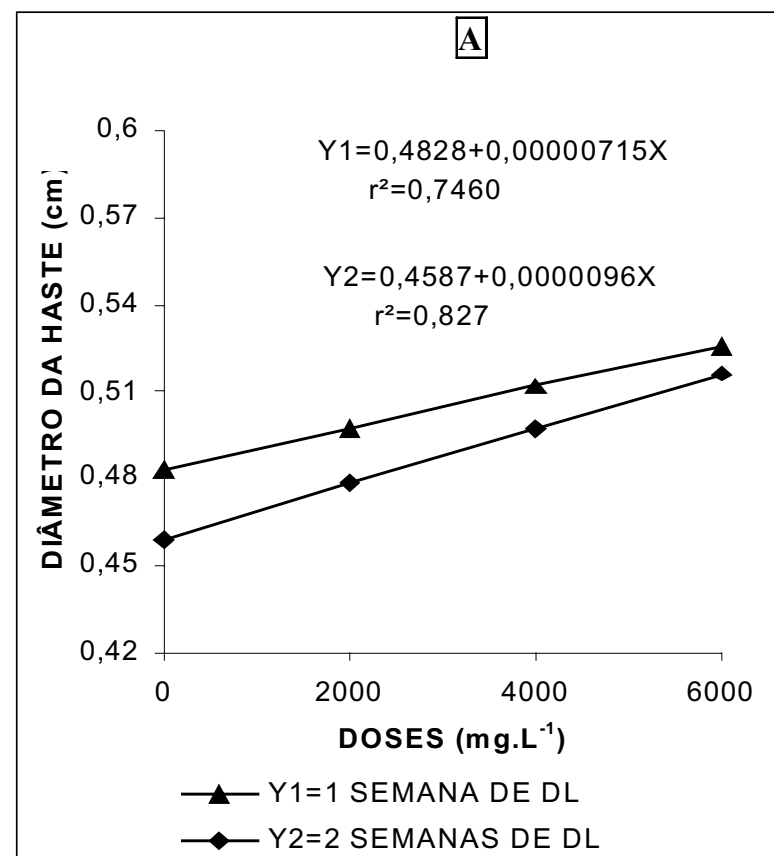

B

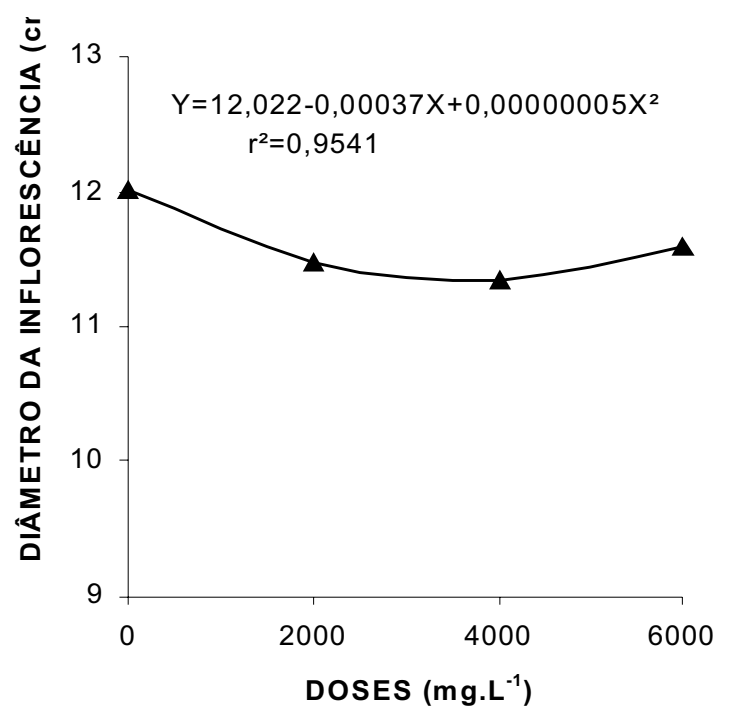

$\longrightarrow Y=1$ SEMANA DE DL

\section{C}

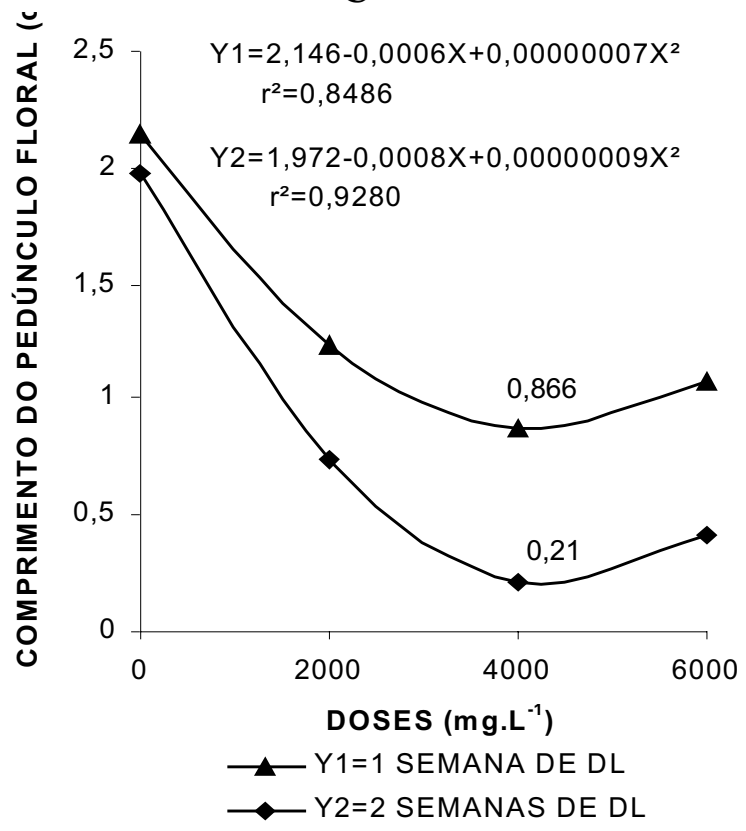

D

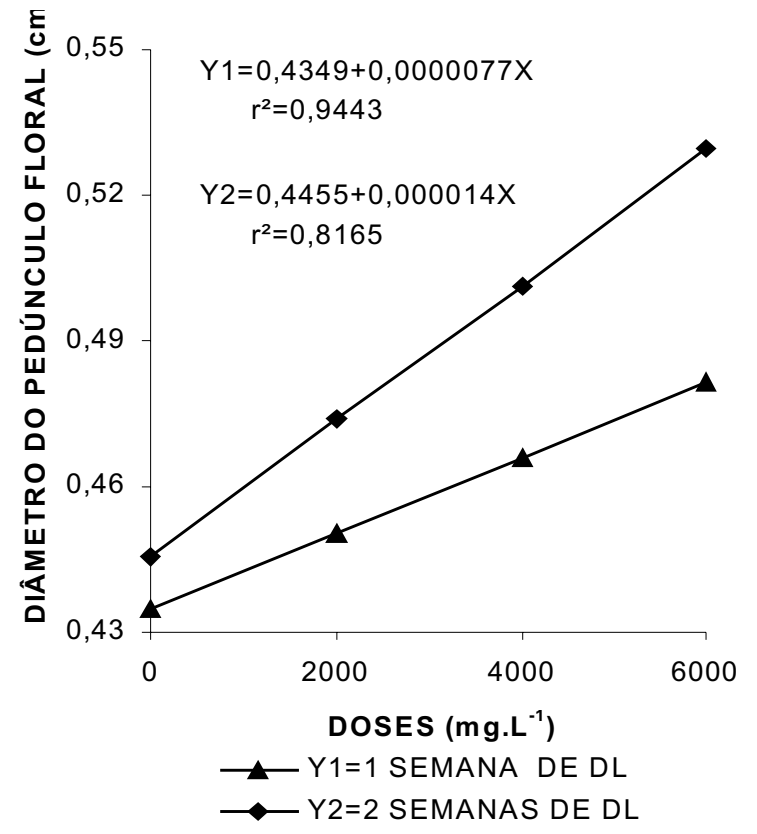

Figura 3 - Diâmetro da haste (A), diâmetro da inflorescência (B), comprimento do pedúnculo floral (C) e diâmetro do pedúnculo floral (D) de crisântemo, cultivar "Snowdon", para doses de Daminozide nos ensaios com uma e duas semanas de dias longos (DL). Santa Maria-RS. 2001.

crescimento, referem-se que não há efeito (YEWALE et al., 1998) ou há redução do tamanho das inflorescências. Assim, foi observado por ELKELTAWI et al. (1996), que as inflorescências de crisântemo tiveram seu diâmetro reduzido em $11,0 \%$ quando tratadas com Daminozide (500 ou $\left.1.000 \mathrm{mg} . \mathrm{L}^{-1}\right)$. Provavelmente a redução do diâmetro da inflorescência ocorre porque o

Ciência Rural, v. 33, n. 6, nov-dez, 2003. 
comprimento das lígulas é diminuído, sem alteração no seu número.

No estudo dos dados de comprimento do pedúnculo floral, constatou-se que, nos dois ensaios, as diferentes doses, submetidas à análise de regressão, reduziram o comprimento do pedúnculo floral (Figura $3 \mathrm{c}$ ). A dose que mais diminuiu esse parâmetro foi com $4.000 \mathrm{mg} . \mathrm{L}^{-1} \mathrm{em}$ ambos os casos. Isso causou redução de 59,64\% e $89,24 \%$ no comprimento do pedículo para os ensaios com uma e duas semanas de DL, respectivamente. As freqüências de aplicações não influenciaram os resultados obtidos (Tabela 2) nos dois ensaios.

Este parâmetro pode ser assimilado à distância do entrenó e, portanto, mostra redução significativa no seu comprimento. Em flores envasadas, o que se deseja é um pedúnculo mais curto e resistente para dar sustentação à flor, principalmente se ela for grande. Quando o pedúnculo possui pouco comprimento, a flor fica mais próxima à folhagem, o que melhora o efeito estético, pois o conjunto torna-se mais compacto, acentuando o contraste flor/folha.

Para o diâmetro do pedúnculo floral, somente as diferentes doses (Tabela 1) influenciaram na resposta obtida. A Figura $3 \mathrm{~d}$ mostra uma resposta linear crescente indicando que ocorreu um aumento de $10,62 \%$ e $18,85 \%$ no diâmetro do pedúnculo floral com o aumento da dose para os ensaios de uma e duas semanas de DL, respectivamente.

\section{CONCLUSÃO}

Nas condições e época em que o trabalho foi realizado e de acordo com os resultados obtidos, pode-se concluir que a cultivar "Snowdon" tem a maior redução de altura de planta, comprimento de entrenós, diâmetro da inflorescência e o comprimento do pedúnculo floral com a dose de $4.000 \mathrm{mg} . \mathrm{L}^{-1} \mathrm{em}$ aplicação semanal. Entretanto, com o aumento das doses, os diâmetros da haste e do pedúnculo floral são aumentados.

\section{REFERÊNCIAS BIBLIOGRÁFICAS}

BARRET, J.E. Mecanisms of action. In: Tips on the use of chemical growth regulators on floriculture crops. Ohio
Florists Association, p.12-18, 1992. Capturado em 23 set. 2000. Online. Disponível na Internet http://www.uesb.br/ flower/reguladores.html.

BELLÉ, R.A. Caderno didático de floricultura. Santa Maria : RAB, 1997. 142 p.

CATHEY, H.M. Comparative plant growth-retarding activities of ancymidol with ACPC, phosfon, chlormequat, and SADH on ornamental plant species. Hort Science, v.10, n.3, p.204$216,1975$.

EL-KELTAWI, N.E., MOUSA, G.T., MAKARY, B.S. Regulation of chrysanthemum growth using GA and Alar to overcome salinity depressions. In: International ${ }^{3}$ symposium on medicinal and aromatic plants. Acta Horticulturae, n.426, p.657-669, 1996.

HARTMANN, H.T., et al. Plant Science: growth, development and utilization of cultivated plants. 2 ed. New Jersey: Regents/Prentice Hall, 1988. Capturado em 23 set. 2000. Online. Disponível na Internet http://www.uesb.br/ flower/reguladores.html.

HERTWIG, K.V. Manual de herbicidas desfolhantes, dessecantes e fitorreguladores. São Paulo : Agronômica Ceres, 1977. Capturado em 23 set. 2000. Online. Disponível na Internet http://www.uesb.br/ flower/reguladores.html.

LOPES, L.C. O cultivo do crisântemo. Viçosa : Universidade Federal Viçosa, 1977. 12 p. (Boletim de extensão, 22.)

MOTOS, J. Produção de crisântemos em vaso. Holambra : Flortec, 1998. 34 p.

NELL, T.A., WILFRED, G.J., HARBAUGH, B.K. Evaluation of application methods of ancymidol and daminozide for height control of Chrysanthemum. Hort Science, v.15, n.6, p.810-811, 1980.

TAIZ, L., ZEIGER, E. Plant physiology. 2 ed. California : The Benjain/Cummings, 1998. 565p.

TAYAMA, H.K. Chrysanthemums (Potted) In: Tips on the use of chemical growth regulators on floriculture crops. Ohio Florists Association, p.40-41, 1992. Capturado em 23 set. 2000. Online. Disponível na Internet http://www.uesb.br/ flower/reguladores.html.

YAMADA, D. Fitoreguladores, In: I SIMPÓSIO BRASILEIRO DE FLORICULTURA E PLANTAS ORNAMENTAIS, Maringá, PR, 1992. Manual de Floricultura... Maringá : Universidade Estadual de Maringá, 1992. p.79-90.

YEWALE, A.K., et al. Effect of growth retardantpaclobutrazol on growth parameters of chrysanthemum. Journal of Soil and Crops, v.8, n.1, p.82-84, 1998. 